\title{
Belgeo
}

\section{The morphogenesis of art districts: Case studies of Williamsburg, NYC and 798, Beijing}

Morphogénèse des quartiers artistiques. Le cas de Williamsburg à New York et 798 à Beijing

\section{Christian Morgner}

\section{(2) OpenEdition}

\section{Journals}

Electronic version

URL: http://journals.openedition.org/belgeo/13234

DOI: $10.4000 /$ belgeo.13234

ISSN: 2294-9135

Publisher:

National Committee of Geography of Belgium, Société Royale Belge de Géographie

Electronic reference

Christian Morgner, «The morphogenesis of art districts: Case studies of Williamsburg, NYC and 798, Beijing », Belgeo [Online], 3 | 2014, Online since 19 December 2014, connection on 01 May 2019. URL http://journals.openedition.org/belgeo/13234 ; DOI : 10.4000/belgeo.13234

This text was automatically generated on 1 May 2019.

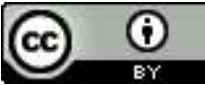

Belgeo est mis à disposition selon les termes de la licence Creative Commons Attribution 4.0 International. 


\section{The morphogenesis of art districts: Case studies of Williamsburg, NYC and 798, Beijing}

Morphogénèse des quartiers artistiques. Le cas de Williamsburg à New York et 798 à Beijing

Christian Morgner

\section{Introduction}

1 Conceptual debates on the rise and decline of art districts often rely on an explicit or implicit use of the gentrification model (Zukin, 1982; Hudson, 1988; Miles, 1995; Ley, 2003; Cameron \& Coaffee, 2005; Curran, 2007; Pratt, 2009; Dörfler, 2010; Harris, 2012). Gentrification often explains urban cultural change as having either organic or preplanned roots ${ }^{1}$. The first model explains that artists (painters, sculptors, dancers, writers etc.) move into derelict, poor or sometimes crime-ridden areas as part of a wider bohemian lifestyle or as a way to find affordable space in which to create. Their presence and activities and their upgrading of spaces changes the atmosphere of the area. By doing so, they transform neglected areas of the city. New shops and bars open, and with the increased flow of economic capital into the area, rents increase and the social configuration of the urban agglomeration is changed, so that the original residents are displaced. With their displacement and the overall upgrading of the area, new cultural entrepreneurs move into the area. They are mostly middle-class and move into these areas because of their bohemian appeal. Rents increase, and boutiques and expensive restaurants move into the area, finally also displacing many artists and related artistic institutions. The district then becomes a residential hotspot for a bohemian middle class.

2 The second model (the preplanned approach) suggests that public policy works as a promoter of urban renaissance, which involves public art and other cultural activities. This approach mainly concerns consumption of art rather than the production of art (as 
in the organic model that mainly deals with artists). Provincialised cities in particular have to rely on public policy to direct their economic regeneration. Arts and culture are seen as means by which to kick-start new economic activities, such as tourism, housing or creative economies. Artistic appeal is increased mostly through public consumption of art through public art installations and events, especially through physical landmarks such as galleries, museums and concert halls. The most prominent examples are certainly the "Bilbao bounce", Gateshead and the Angel of the North or the well-known transformation of Glasgow after being the European Capital of Culture (Bailoni, 2014; Comunian \& Mould, 2014).

3 Both models discuss urban cultural change through a perspective of decline. Furthermore, the gentrification model is often restricted to the urban dynamic of a particular area and does not embed this transformation into the wider urban dynamic. Additionally, gentrification explanations are often based on single case studies in the Western world and do not compare their findings with non-Western city-regions. Finally, the conditions that enabled a particular district to become an art district tend to be quite general and mostly related to an economically inspired framework ${ }^{2}$. The difficulty of such economic explanations is that they do not account for a cultural understanding of urban history and lack an evolutionary understanding of "why here" and "why now". For instance, metropolitan areas consist of many poor or underdeveloped districts, but not all of them attract artists or develop into artistic districts. Furthermore, the average rent in metropolitan areas is generally much higher than in the countryside; if the low-income situation of many artists were the main driver, then artists would be much better off if they were away from such cities, and rural areas would presumably become "gentrified". It seems that the overall economic logic originating from gentrification studies is unable to explain the overall historical development of urban art districts.

4 Thus, in order to develop such a general urban historical framework, attention will be paid to a more evolutionist vocabulary, namely that of morphogenesis, using this vocabulary from an interdisciplinary perspective which includes sociological, historical, geographical and ethnographic considerations. As will be discussed later in more detail, morphogenesis is based on an understanding of a build-up of social complexity and thereby pays attention to more conceptual aspects through which evolutionary changes can be studied. The important aspect of this kind of evolutionary approach is to stress that the build-up of social complexity is an improbable process which requires social conditions that make the unlikely evolution of the complex urban setting possible. The task is therefore not only to identify aspects that could be considered relevant factors but to explain how these conditions support and maintain the transformation into higher complexity. (The important role of "how" instead of "what" questions is discussed by Denzin, 1983). This transformation will be conceptualised through identifying conditions in the here and now, based on two case studies, Williamsburg, New York City (NYC) and Beijing 798, which can then be implemented into a broader framework of urban cultural change.

5 In the first part of this paper, the term "morphogenesis" and its role in evolutionary theory will be discussed. Particular attention will be paid to improbability theorem. The second part of the paper describes the case studies of Williamsburg, NYC, and Beijing 798 that will provide the empirical context. Historical research into the formation of art districts is rather scarce (Gee \& Steward, 1995), and most of these studies lack in-depth empirical material and instead retell public stories and urban imaginaries as reported in 
the media. Relevant empirical data thus had to be collected. These case studies represent art districts from two different cultural regions (the Western world and the Far East) and allow for some comparative assessment. The third part of this paper presents three barriers of improbability as part of the morphogenesis of these districts. These barriers will look at key features in the spatial-urban settings of Williamsburg, NYC, and Beijing 798, with particular attention being paid to how these districts managed to become successful in contrast to others in the same city-region. This part will also address the improbable conditions under which a minority of people (artists) can take over an entire district, and finally, this paper will discuss how likely it is for art districts to survive in the long term.

\section{The theory of evolution and the concept of morphogenesis}

6 Theories of evolution encompass a wide field of disciplines including biology, sociology, urban studies, geography, history and economics. One of the central concerns of evolutionary theory is the principle of selection and how selections react upon other selections, leading to further selections. An important consideration stresses the improbability of creating complexity based on such an uncoordinated selection of selections or how such an undefined state can be transformed into a defined state. ("Uncoordinated" means that there is no religious master plan). This transformative aspect will be discussed using the concept of morphogenesis.

7 "Morphogenesis" is a well-known term in urban history and urban studies (Gregory, 2000; Kropf, 2001). Research in this area includes the study of the forms of human settlements (metropolitan areas, cities, towns or villages), patterns of land use and ownership and how humans react to their physical environment and vice versa (Park, 1928). In this paper, an approach is stressed which highlights the role of complexity and improbability in combination with the formation of social structures (Archer, 2013). Herbert Spencer stated that the evolution of forms, or morphogenesis, is a "change from a State of indefinite, incoherent homogeneity to a State of definite, coherent heterogeneity" (Spencer, 1898, p. 353). Evolutionary theory then asks how it is possible that more and more complex forms can be built and function normally when such a complex build-up is improbable (Morian, 1977). This question has also been addressed in more sociological theories of evolution that link the issue of morphogenesis to that of complexity by dealing with the paradox of the "probable of the improbable" (Luhmann, 2012, p. 251). These theories question how even more complex social structures and societies can develop despite this being an unlikely outcome. For instance, Christian Lefèvre (2010) demonstrates in his paper, "The Improbable Metropolis", the sheer unlikeliness of all necessary aspects (technologies, knowledge, timing, legal regulation, socialisation) coming together to allow a metropolitan area to emerge. The topic of this paper, the rise and decline of art districts, could be seen as an example of such a highly improbable phenomenon. Organically developed art districts on a larger scale are very rare and appear in only a few cities around the globe. Furthermore, art districts are very complex social fields. One can imagine that their occurrence requires the right timing and social atmosphere, sufficient architecture and non-regulated settings (no existing institutional dominance). These districts also tend to exist only for a relatively short time, while complex structures usually need considerable time to be built up. Nevertheless, although 
art districts are highly improbable phenomena from an evolutionary perspective, they are a famous feature of urban history. How is this morphogenesis of complexity possible, and how is the improbable occurrence of art districts made possible in urban evolution?

\section{Case studies and data}

8 Most of the studies dealing with art districts and urban history are single-case studies and come from the Western hemisphere, such as accounts of early $20^{\text {th }}$-century Paris (Guilbaut, 1990) or New York City (McFarland, 2001) or of contemporary London or Berlin. (An interesting exception to this is the study by Boichot, 2014). Consequently, their application to other districts, particularly in non-Western regions, is difficult. There is a lack of systematic comparisons on which to base generalisations from which a theoretical model could be drawn. A Grounded Theory (Glaser \& Strauss, 1967) approach suggests comparing cases that have aspects in common but which are also different from each other. This comparative approach is known as that of minimal and maximal contrast. The differential nature of the cases allows for the development of a broader framework, and the shared features enable the different empirical cases to be linked into such a frame of reference. Based on this idea, the paper has selected two cases, Williamsburg, NYC, and Beijing 798. New York City has been a global art city for several decades and has a long-standing reputation in this field. However, the picture we have of New York is mostly influenced by SoHo, and more recent research mostly addresses shifts in the art market but not in the art world (Molotch \& Treskon, 2009). New York is considered a global art city in the Western world. Beijing is a much more recent art city, but the rise of the visual art world in China as a whole has been rapid, with China in the last decade becoming the largest visual art market after the United States. Beijing has become another global hub in the world of art and culture but has also become an important economic centre in China. Although these cities seem to be very different in terms of their artistic development, political context and reputation, they also share certain features.

Williamsburg is a neighbourhood in the New York City borough of Brooklyn. It is located on the east side of the East River, just one metro stop away from Manhattan (Figure 1). Many ethnic enclaves are located in the area. Small numbers of artists have lived in the area throughout the $20^{\text {th }}$ century, but the first significant portion moved there during the 1970s and, in particular, the early 1980s. This continued throughout later years and increased significantly in the 1990s. By then, Williamsburg had become a prime art spot, overtaking SoHo and the East Village. It is said that in the mid-1990s, around 3000 artists lived in the area, attracting international visitors to a cutting-edge art scene (Pflaum, n.d.). Soon galleries, music venues and theatre spaces opened. The district is said to have "peaked" in 2000, after which some of the artists began to leave and move deeper into Brooklyn. Currently, Bushwick, on the western side of Williamsburg, seems to be the upand-coming art district. The time frame for Williamsburg will mainly focus on 1980-2008.

The 798 Art Zone, or Dashanzi Art District, is an art district in the north-eastern part of Beijing. It is home to a number of decommissioned military factories. The number 798 derives from factory building number 798, but it actually applies across several complexes. The factory was vacated in the later 1980s, and large parts of the area fell into decay. In 1995, Beijing's Central Academy of Fine Arts (CAFA) was closed down, and the artists in Beijing's sole art district were evicted from its premises near the old Summer 
Palace. The academy was supposed to get new premises on the outskirts of the city. However, no appropriate buildings had been constructed near the 798 area (there was a lack of large studio spaces), and the staff of the university had to look elsewhere. They found a number of empty buildings nearby and started to rent them (there were no artists previously living in the area). Over the following year, more and more artists moved into the complex. Famous Chinese artists who had lived abroad returned to the area. (They were encouraged by the opening of the Chinese Pavilion at the Venice Biennial in the late 1990s; Hung, 2008). The first professional foreign gallery opened in 2001, and later, the first art café opened and the first art festivals occurred. The latter received considerable international attention, causing even more artists to move there. More and more galleries opened. With the international attention, the government began to intervene (removing works of art that included nudity or were considered politically offensive), particularly in the period before the Olympic Games of 2008. Some of the more controversial artists were made to leave the area. Additionally, the district became more fashionable and a tourist hotspot for Chinese tourists in particular. The district has been transformed from being a place of artistic production into a place of cultural consumption between 1995 and 2012, resulting in rather sarcastic labels such as 798 being a cultural zoo.

11 The data was collected based on ethnographic research and in-depth interviews conducted in NYC in 2010, when the author lived in Williamsburg for six months, and during a second research trip to Beijing, where the author stayed for three months in 2012. Most of the artists who have lived or live in those districts are still alive and can be interviewed. About 40 in-depth interviews were conducted in the course of these two research trips. They were based on semi-open questionnaires and were between one and two hours long. The interviews were transcribed and analysed using the qualitative analysis software, Atlas.ti. In addition, newspaper material, flyers, leaflets and other documents (including pre-existing literature) were taken into account.

\section{The improbability of art districts: three barriers}

12 This paper will address three important barriers to the morphogenesis of art districts, which are repeatedly discussed in the literature (Palenzuela, 1986; Cohen, 1991; Shank, 1994; Foord, 1999; Green, 1999; Santagata, 2002; Montgomery, 2003; Wu, 2005; Cinti, 2007; Cooke, 2007; Ambrosino, 2008; Molotch \& Treskon, 2009; Bader \& Scharenberg, 2010; Stern \& Seifert, 2010) but for which empirical evidence and theoretical concepts are scarce.

- How can a complex spatial-urban setting or a particular place arise as an art district rather than other parts of the city?

- How can a small group of people take over the symbolic means (representations, narratives, norms) of an entire area or district?

- Is it likely for an art district to survive in the long run?

The first barrier addresses the question of why a particular area develops into an art district. The "qualities" of the area are not initially known and are often revealed only with the artists' presence. There are often, in principle, many similar areas to which artists could go, and even if artists begin to cluster in a particular area, there is a great possibility that others will not follow or that the artists will be quickly driven out by other factors (cf. question three). 
None of the areas in this study that became art districts was densely populated by artists. The areas were dominated by a range of other structures, including the native population, business structures and, most important, symbolic images (urban imaginaries, representations and norms associated with neighbourhood's or city's history).

The second question examines how it is possible that a small group of people can transform the image of a district. How can they make others believe in the change?

The third question relates to the organic model of gentrification. This theory seems to suggest that art districts are unlikely to prevail in the long term. However, this paper will demonstrate that the lifespan of an art district is strongly related to its own growth and is only influenced to a minor extent by external factors.

\section{First barrier: the improbability of selecting a particular area}

Evolutionary dynamics are concerned with the problem of variation and selection (Bergstrom \& Dugatkin, 2012). Variations occur all the same, but only a few are selected and integrated into broader structures. The improbability relates to the question of why, out of a vast number of variations, some are selected and not others (Morin, 1977). Trialand-error explanations are considered insufficient, because their haphazard nature does not explain the pace and complexity of evolutionary dynamics. The concept of morphogenesis is thus concerned with the question of how these heterogeneous variation selections and thereby the formation of complex structures can become possible. The formation of art districts shares a similar question. There are many areas in a city that could become art districts, but usually only one or two really make it. This evolutionary uncertainty is often illustrated in rational choice terms (Skyrms, 2014). It is not certain which area might become the next hotspot; thus, any kind of commitment to a particular area comes with the danger of having relocated to the non-hotspot and thereby being excluded from an important set-up, vibrant activities and integration into the art market. However, it is also not rational to wait, because the waiting might imply being too late. Thus, there is an evolutionary dilemma in which no structures will evolve if that oscillation between different states is not overcome. To overcome this improbability, evolutionary theory argues that structural devices that evolved elsewhere or in a different context may channel or reinforce selections and thereby create a path dependence out of which more complex structures can evolve. This part of the paper is therefore concerned with the structural devices that nourished the development of particular areas over others.

What could be seen as the beginning of both Williamsburg and 798 is marked by the decline of other art districts - in these cases, the end of SoHo as an art district and the closure of the Central Academy of Fine Arts (CAFA) in central Beijing ${ }^{3}$. Those declines, however, are not marked by a collective movement in which all the artists simply relocate. The decline is, rather, a slow process in which some people leave for elsewhere; some might leave the city or even stop doing art altogether. For those who stay in the city seeking a new district, but who have none available, there is a tendency to live a rather nomadic life. 
Figure 1. Relocation of NYC-based artists, 1970s-2010s.

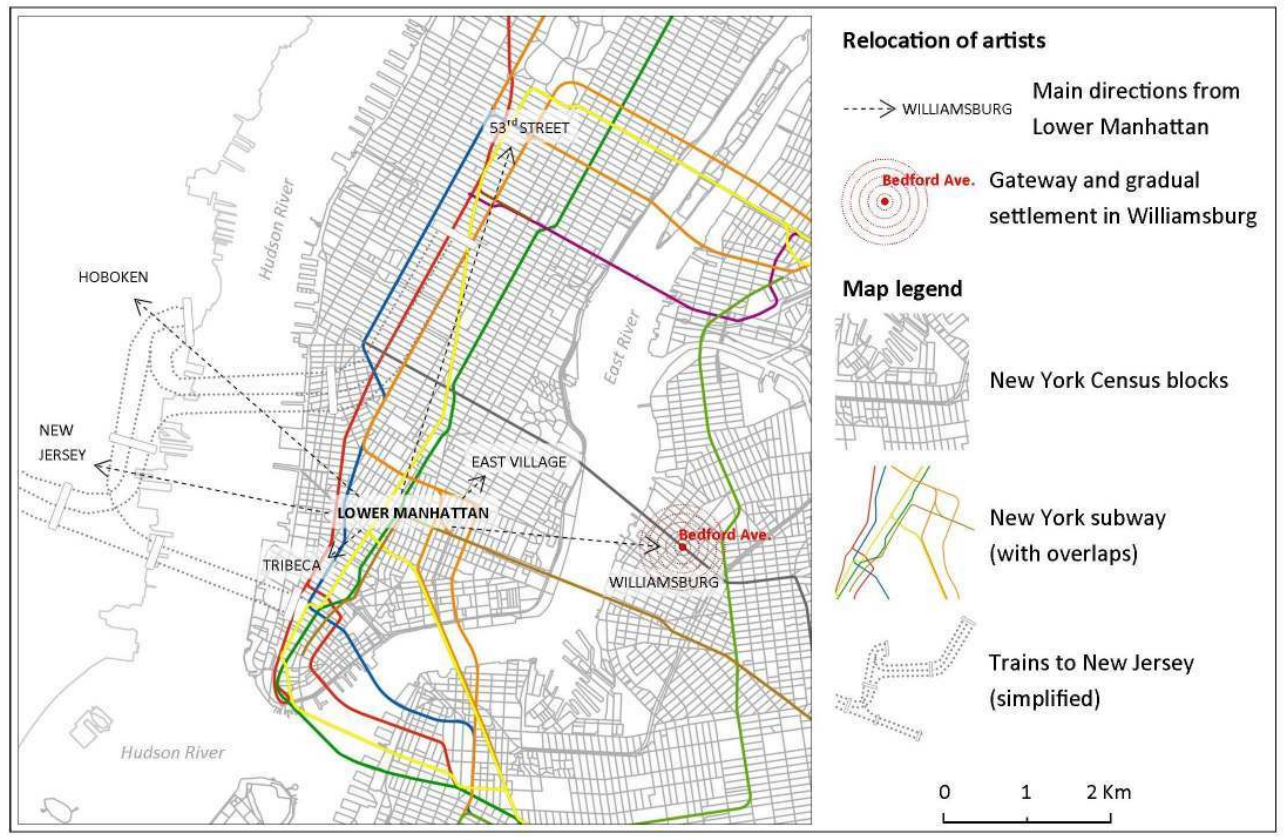

Sources: NYC Census blocks

(http://www.nyc.gov/html/dcp/html/bytes/districts_download_metadata.shtml); subway routes ( http://spatialityblog.com/2010/07/08/mta-gis-data-update/); own digitalisation of PATH train lines ( http://www.panynj.gov/path/maps.html); New Jersey counties (https://njgin.state.nj.us/ NJ_NJGINExplorer/DataDownloads.jsp).

Cartography: Tatiana Debroux \& Christian Morgner, 2015

In New York City, the artistic life of SoHo came to a slow end in the 1970s and early 1980s. (Simpson, 1981, tells fully the story of the rise and decline of SoHo.) As shown in Figure 1, the artists who left the district as a result moved to different areas. It is difficult to provide exact statistical figures or an exact timeline for this relocation. However, the research in this area indicates that in the late 1970s and early 1980s, several hundred artists had relocated to Hoboken, New Jersey, mostly along the PATH train route (Cole, 1987 and Figure 1), and to the East Village. A small number of mostly established artists moved uptown, while a much larger number of those who wished to stay near the area moved into bordering TriBeCa. A small number of artists in their mid-careers moved into Williamsburg. Of those areas, TriBeCa and the East Village were expected to become new art districts, because a number of artists moved together and looked likely to replicate the SoHo effect in those areas. However, this was all very short-lived, and after little more than a few years, diverse and vibrant artistic activities ceased. In sum, for about 10 years, no coherent artistic district existed in NYC.

Evolutionary theory would describe this state as a loose coupling (Sundbo \& Gallouj, 2000). Coupling refers to the degree of direct interaction or exchange that one part or component has with another. A high artistic diversity can be reached if a larger number of artistic activities (components) can be linked or interact with each other. The beneficial effect of this interlinking can be seen in knowledge spillovers, in the creation of testing grounds and in collaboration as well as competition. In such a setting, strong couplings (cohesion) can emerge. This picture is very similar to the situation in Beijing, even if the context differs. 
Figure 2. Relocation of Beijing-based artists 1990s-2010s.



SOURCES: HTTP://DOWNLOAD.BBBIKE.ORg/OSM/BBBIKE/BEIJINg/ (ROAD NETWORK GENERATED FROM OPEN STREET MAP)

CARTOgRAPHY: TATIANA DEBROUX \& CHRISTIAN MORgNER, 2015.

21 Figure 2 illustrates the spatial distribution and relocation of artists based in Beijing in the early 1990s. Due to the political situation in China, the avant-garde art or artists that did not follow the regime have traditionally existed only on the fringes of Beijing. They were not located in the city centre, but the only concentration of such artists (several hundred artists) was found near the Old Summer Palace in north-western Beijing (Figure 2). That area was closed down in the early 1990s by local authorities, and the artists were forced to move elsewhere and so spread across the city. The number of artists searching for a new home increased when Beijing's Central Academy of Fine Arts (CAFA), located in the city centre, was closed down and went looking for space elsewhere. A great number of artists thus spread across the city, living a rather nomadic life with no visible clustering of artistic activities. Furthermore, China and, in particular, Beijing underwent an enormous transformation. In 1990, about 10 million people lived in Beijing. By 2014, the size of the population had more than doubled and reached about 21 million inhabitants (City Population, 2014). Urban land expansion and morphological change in Beijing transformed the urban layout, lifestyle patterns and economic situation almost on a daily basis (Gaubatz, 1999; Gu \& Shen, 2003; Tan et al., 2005). Under these conditions, a communal coming together was extremely unlikely, because further developments remained in the oscillating state of not knowing if one should stay or move elsewhere.

The dissolution and dispersion of the artists in both cities resulted in a heterogonous state, but why, then, did Williamsburg and 798 come into being? As mentioned before, an answer to that question would have to demonstrate by what means or structural devices unlikely combinations could become more likely and be reinforced and amplified (Luhmann, 2012, p. 253).

\section{Spatial accessibility and urban morphology}

This part will demonstrate the asymmetrical function of spatial access and its structural implications for the channelling of evolutionary dynamics. The asymmetrical quality 
means that a very heterogeneous and symmetrical state might lead to greater complexity if structural developments favour a particular selection. Urban access plays an important role in making some areas more likely than others to become homes to artists and to develop art districts (Glaeser, Kahn \& Rappaport, 2008). In New York City, the metro system ensures good access to many parts of the city. Access, however, does not refer to the ability of the artists to travel easily to an area, but to the fact that the area where they work is connected to the relevant artistic infrastructure (galleries, museums, bars, pubs, theatres, music venues, literary agents). If artists want to exhibit or go to bars and music events for the development of their careers, they cannot rely on new art districts, as these districts will not yet have these structures in place. Thus, to stay in touch with the art world, artists must be able to reach these institutions easily. Public transport, then, may reduce the probability of being excluded, because it provides access to a pre-existing complex of structures.

Furthermore, the metro system provides access that does not require preplanning, contrary to other transportation means such as a railway, and therefore is more convenient to the structuring of artistic activities and creativity. The area along the PATH train (Figure 1) meant that the artists had to rely on a transportation system that was not made for spontaneous activities, and furthermore, the fact that one was in New Jersey meant that one was not in NYC anymore, a symbolically powerful difference.

Access has a second function in that it also works as a shield. If an area is very accessible to surrounding institutions, then a potential arts district might easily be driven out by other developments (for the example of Seoul, see Kim, 2007). This helps to explain why some of the seedbed communities, for instance, in TriBeCa and the East Village, survived for a short time only (Cole, 1987). TriBeCa was basically an extension of SoHo and was soon overwhelmed by the extension of commercial activities from SoHo (Figure 1). The East Village also quickly came into prominence; it was very accessible, it had clubs and nightlife and it could be reached from various parts of Manhattan, the prime centre of cultural activities. It was then occupied and transformed by these other activities moving in. Access to Williamsburg was a double-edged sword for the following reasons:

1. It is just one metro stop away from Manhattan (Figure 1, L-train to Bedford Avenue). Edward Winkleman, former owner of Plus Ultra Gallery in Williamsburg, explained: "The L-Train which was our most popular way to get to Williamsburg." This nearness and access was important, because it enabled artists to have their studios across the river, but they could easily access the East Village, which had the main infrastructure in the early 1980s. Daniel Aycok, the owner of Front Room Gallery, illustrates this: "So there were parties all the time and people would have art parties and things like that, but mostly people who lived here hung out in the East Village still because that's where all the things were." The loose coupling of artistic activities that emerged in Williamsburg allowed artists to maintain their ties with the art world due to that access. They were thus not disconnected from artistic innovations, their peers or an artistic atmosphere. Talcott Parsons calls such arrangements of social and spatial differentiation in combination with complex forms of interaction evolutionary universals (Parsons, 1964). Evolutionary universals provide higher forms of integration in complex and loosely connected states and thereby enable improbable arrangements to be realised.

2. Williamsburg is based in Brooklyn and is therefore outside the symbolic centre of the city. Although Manhattan is another district in NYC, it is often seen or described as the real NYC, and parts outside of Manhattan do not really belong to NYC (the statements in Table 2 illustrate this). This form of symbolic disconnection, however, initially shielded 
Williamsburg from being quickly gentrified. As Hardin (1960) discusses, such an evolutionary niche is important for loosely coupled social formations. They cannot yet compete due to a lack of resources and infrastructure but are given a space in which they can experiment and test out inventions that might became leading innovations. model. The vast urban extension of Beijing is linked to a modern metro system, but not in all parts of the city (Figure 2). There is no metro station in the vicinity of 798, and it is relatively complicated and time-consuming to go there by bus. This exclusion from transport has caused the area to remain quite underdeveloped in contrast to other rapidly advancing parts of the city. Urban transformation and extension in Beijing brought enormous changes to the urban morphology, but it did so through a combination of road rings (there are now seven ever increasing ring roads) and a centre/periphery metro network (people come directly into the city from the outskirts and go back on the same direct route) which does not allow much connection among areas between the centre and periphery. In this sense, the 798 area was a bit off the map, as it has fallen between the more accessible areas.

However, with the closure of the Beijing art academy (CAFA) and relocation to that area, things changed. The relocation of the art academy was nevertheless done only with the core buildings being constructed but without constructing large studio buildings and work spaces. In the late 1990s, the sculpture department of CAFA had to commission a monumental sculpture for the Chinese government of the war between China and Japan. Sui Jiangu was at that time the head of the sculpture department and explains: "Because it's very big, so the department thought maybe we have to find us some big space to do the sculpture. So in that time, we know around the place some old factory and that closed a long time." They found the place by simply walking around in the area and talking to locals and thereby discovered these empty spaces, in principle, by chance. The space being within walking distance to their campus ensured that they had the necessary access to infrastructure in which artistic production could evolve. Thus, the linking of the art academy and new spaces provided an evolutionary anchor. Initially, 20 teachers worked on the sculpture, but the department invited young sculptors from all over China to collaborate. The number of artists working on the piece grew to 40 and later on, to about 80 to 100 artists. When the commission was completed, the artists had grown fond of the place and extended their lease with the landlord.

Based on this initial network of artists and through the academy, nearby more and more artists were drawn to the area. However, 798's location also meant that it was reasonably distant from the city and therefore not easily overwhelmed by its rapid urban transformation, allowing the art district to develop (Huang, 2004). Furthermore, 798 was also excluded from the symbolic space that had taken over Beijing. The drive for newness and economic prosperity became a dominant narrative in the early 1990s (Ren, 2008; Smith, 2008) and would influence urban change and the envisaged image of the future city. Areas that could easily be incorporated into this modernist narrative were rapidly transformed. However, the former factories in 798 could not easily be sold off, as the Maoist wall paintings and socialist decorations gave some sort of protection, but they were also unattractive for adaptation to the modernist drive. The symbolic setting of those buildings remained in a liminal state. This liminal state of not belonging to the old or the new regime provided a shielding function under which the artists could operate and flourish. 
Access is a precondition upon which order can develop. It provides an anchoring function through which an even distribution of artists spread across a city can be influenced, creating conditions in which more complex developments become possible but also more improbable. Access itself, however, is not sufficient to give direction to a loose and heterogamous grouping of artistic activities within a city. The cultural and symbolic configuration of cities' districts, and therefore their urban history, the narrative of the city, is itself also important (Lefebvre, 1991).

\section{Urban narratives and imaginaries}

Another important evolutionary device is urban narratives or imaginaries. This part demonstrates that an urban narrative of free space, open space or ignored space is another important evolutionary device for the channelling of complexity. These narratives create another type of asymmetrical symbolism that suggests where artistic production in city is probable and where it is not. These narratives are therefore not simply stories about a particular area, but they are narrative devices that concern the whole urban dynamic.

31 Artists tend to talk a lot about space, increasing rents, and retail, as reflected in the following statements (Table 1). The notion of space is so important simply because space is related to symbolic freedom (Claval, 1984).

Table 1. Freedom as Open Space and Blending In.

"So it was a lot of space, and by Manhattan standards, it was just incredible."

(Aron Namenwirth, artist based in Williamsburg)

"There were a lot of vacant fields, which was beautiful."

(Luisa Caldwell, artist based in Williamsburg)

"[There was a] punk feeling to it, you know, there was a feeling there was going to be something because we had these spaces here nobody [was] using."

(Matt Freedman, artist based in Bushwick)

"I've seen 798 gave us really, we have very fresh...we have fresh air, you know, very free, you know. We're artists, we are happy to find a free place."

(Zhao Bandi, artist based in Beijing)

"[The thing about being] in this big space, is you felt that you needed do some big work."

(Sui Jianguo, artist based in Beijing)

"In the Factory, there is a strong spatial contrast because the space size is bigger, and other art material won't become distractions."

(Huang Rui, artist based in Beijing)

An area that is open or big gives an artist the opportunity to do a number of things - it provides possibilities. Space is like an empty stage in a theatre, where no play exists and which is not yet dominated by a strong narrative and can therefore accommodate artistic freedom of expression. This open atmosphere, however, is not attractive to all artists. The 
term "artist" has thus far been used in a very general sense, as if all artists possess the same motives and desires. Nonetheless, artists might share different generational features depending on whether they are emerging or established. Large, open space appeals in particular to those who initially want to find a place just to work, while others are looking for a place to live the lifestyle of an artist and therefore require a more developed symbolic infrastructure. They make different investments (workspace, lifestyle) and thereby feed the cycle of the morphogenesis of art districts.

The spatial history of a cycle of creation and decline is not available for every city and its districts or neighbourhoods but can provide a partial answer as to why some cities have better potential to attract artists; they possess an urban dynamic in which districts can rise but also decay. A city being homogenised, for instance, through being dominated by a residential or by a consumerist symbolic complex does not provide an urban dynamic in which such spaces can open up or be opened up. Thus, symbolic self-definition through a city's cultural resources is an important resource in the build-up of artistic districts, as it provides a symbolic framing upon which further artistic activities can be built and with which they can be linked. Akin to this is another important concept, that of the outsider and the notion of the deviant lifestyle, which derives from the wider symbolic discourse of the city, in which each district shapes an image that can stand in contrast to others. This notion is reflected through the symbolic paradox of being the outsider but also the pioneer (Vivant \& Charmes, 2008). The following quotations demonstrate the symbolic configuration and importance of performing of being an outsider and thereby a pioneer at the same time:

Table 2. Outsider versus Pioneer.

"When I moved to New York City, somebody told me that I'd be living in Brooklyn." (Luisa Caldwell, artists based in Williamsburg)

"And I remember really specifically that she told me that she didn't want to be a ' Brooklyn loser'. And the other thing that I knew - I can tell you millions of stories, but I had a job in Manhattan working in a magazine, and people were always saying, 'Where do you live?' And I would say, 'Oh, I live in Williamsburg,' and they would go, 'Oh. Well, I didn't move to New York to live in Williamsburg. I moved here from Ohio to live in New York.' Like they would actually make it clear that this was not New York."

(Amy Sillman, artist based in Williamsburg)

"So...the whole area is just...is an old factory, at that time. No water, no atmosphere... it can be an art area because we don't think that the house is good, you know...There are poor [people] living inside the area...First, they were very surprised, you know. “ You live up here?"'

(Zhao Bandi, artist based in 798)

"It was very dangerous, big open spaces, they were really, really cheap, nobody wanted to live there. Richard Sarah, Nancy Graves, a whole bunch of people just came into these spaces where nobody wanted to live. Big spaces, very low rent and it's in a place where it's very rough. That was Williamsburg too. Big spaces, very unsafe, low 
rent, close to the city."

(Aaron Namenwirth, artist based in Williamsburg)

As illustrated in these quotes, the outsider or outcast is someone who does not live within the dominating symbolic space of the urban landscape; as well, the rules of the game, so to speak, are spurned and disrespected. The artists stated in the interviews that a consumerist attitude in central New York City or the political cleanness in central Beijing is to be avoided, as this would interfere with their artistic expression and production. However, in combination with the notion of the pioneer, the outlaw is transformed into someone who goes before others, who can cope with wilderness, who leads. He or she is not a person who follows a trend, who copies, but someone who is original, authentic and innovative - and therefore able to influence others (Stratton, 1977). In this sense, the potential artistic district in which the outsider settles provides an urban narrative upon which an evolutionary dynamic can unfold in building up artistic identities. In the context of evolutionary theory (Padgett \& Ansell, 1993), it can be argued that the notion of a periphery is created. However, this periphery reflects a sort of deliberate exclusion. This narrative of exclusion suggests that in the centre, innovations or artistic production have been rendered improbable, because the freedom of expression is constrained by established traditions, the needs of the art market or a general climate of cultural consumption rather than production. The periphery is thereby marked at a place of innovation, where artistic production is highly probable.

In sum, the urban dynamic of some cities, along with their cultural history, their social differentiation and their economic dynamics, provide room for serendipity. Unlikely combinations can be tested, and if successful, more complex urban imaginaries can emerge, which then create a dependence on the area and can "localise" artists but also provide ties to wider developments in the city and make the district more attractive for other artists. If such anchor points are established and can be maintained (for instance, having no competition with other urban functions or actors), path dependence is set in motion. Path dependence then means that likely occurrences condense into expectations. One can be more certain of what kind of evolutionary dynamic will unfold. The uncertainty of place and production are managed, and a preference for a particular location is set in motion.

\section{Second barrier. the improbability of a minority becoming the majority}

To this point, this paper has discussed particular qualities of an area that could make it attractive to artists, in contrast to other areas. However, the confirmation of these qualities requires not only that a small group makes this claim but that a greater number of artists reflects and disseminates this practice. The underlying evolutionary problem is that actors have several alternatives, and the costs and benefits of these alternatives greatly depend on how many other actors may choose the same alternative. The key concept here is that of a threshold (Granovetter, 1978), which implies the question of how a small group of people can take over an area that has a rich urban history and symbolic representation and be able to change it. Very often, such areas are crime-ridden or seem uninhabitable and are dominated by histories of violence, ethnic segregation or urban 
decay. The empirical analysis suggests that four aspects play an important role in overcoming these obstacles.

\section{Spatial configuration and social interaction} access to public transport, the housing situation and the social climate, in combination with social interactions - may provide a threshold model that can lead to a growth in social complexity where a minority can finally become the majority.

41 The crime-ridden or uninhabitable image of the district causes artists to settle in proximity to the sole metro station (Figure 1: see inner circle and Bedford Avenue), which is also only one stop from Manhattan, allowing the artists to remain close to the galleries, music and theatre venues. They can thus slip into their studios almost unnoticed by the local population (a fact often mentioned in the interviews conducted for this study). However, this spatial proximity causes the artists to bump into each other on a regular basis. They see each other on the station's platform or in the nearby shops. They thus realise that they are not alone. The spatial configuration thereby enables these regular encounters to occur. Based on these frequent interactions, more complex social structures and, in particular, networks of artists develop (Figure 1: the artists spread into Williamsburg), which then results in the formation of friendships, mutual invitations to parties etc., causing a small community to arise that fosters innovation. (The role of networks and evolutionary dynamics of innovation is discussed by Newman, 2003).

In this network, the artists motivate and protect each other. For instance, in Williamsburg, many artists bought large dogs and then would accompany friends to the 
station or to their studios if they lay a bit farther out in the district. Other examples of protection include artists going out in groups. A safe zone is created in which a sense of community develops. When this threshold has reached a sufficient proportion of artists living and working successfully in this area, other artists can move in under the material and symbolic protection of this community. This has a cumulative effect, and the safe zone expands over time. Evolutionary theory refers to this as positive feedback, where the same results are applied to previous results, thereby reinforcing them (Arthur, 1990). Under these conditions, it becomes more likely that more and more artists will move into an area and become the dominant group. Thus, spatial configuration and resulting local interaction are crucial for the morphogenesis of art districts.

\section{Social ignorance}

As mentioned above, there are several criteria in the spatial configuration and social setting that came up in the empirical data and which contribute to the morphogenesis of art districts. The aspect of social ignorance refers to a non-competitive setting in which new and existing spatial imaginaries coexist. Evolutionary theory suggests that in such a non-competitive setting, niche activities can flourish or coexist with other social settings (Park \& Feiock, 2006). In contrast to that, if a district has a fixed and competitive social configuration, like a very residential or commercial district, it would become highly unlikely that artists could carry on their experimental activities there, because they would be overpowered by that urban configuration (Hanquinet, Savage \& Callier, 2012). Rather, they require a social configuration in which no one cares about what the artists are doing. They can build a massive sculpture in the middle of a street or play loud music at openings. Daniel Aycock, the owner of the Front Room Gallery, gives an example of this: "Whenever we have [an] opening at the gallery we have to be absolutely sure nobody walks out with a glass of wine because if they're standing outside the door with a glass of wine the police will pull up like that and give them a ticket. If they see a crowd they will pull over and give everybody tickets. You used to be able to stand out in the street and have some performance with beer and stuff and nobody cared." The locals ideally would not be bothered by this, either because the district features a diverse mix of cultures and therefore has a high tolerance threshold or because the area's problems (for instance, a high crime rate) mean it simply has other priorities. Williamsburg had a high crime rate, with local gangs controlling certain areas, and the former textile and sugar industry had vanished, leaving many empty buildings behind. Police and public services were virtually not present.

The area in 798 had undergone a rapid economic decline. Factories had closed in a short time frame. The local authorities struggled to rent out the buildings, were happy about any kind of interest and did not really bother about what the artists would do in there. Sui Jianguo, an artist formerly based in 798, states, "The 798 is good because no one checks [censors] your show. Yeah, if you want to show in some offices there's maybe someone [to] try to check your... your work, you know. In that place no, it never happened."

It is not only the space that provides freedom, but the artists must not be limited in their social lives. This is very important, because this social freedom, in particular from the art market, also provides time as an evolutionary resource. It means that artists are not under any pressure to produce and can thus experiment a lot, trying out different media, material etc. Thus, they can develop enormous artistic complexity, disconnected from 
any kind of mainstream art market. The importance of having time, and the role of time in this evolution, cannot be overestimated here. As Csikszentmihalyi (1999, p. 316) has pointed out, creativity can be seen as a special case of evolution: "To be creative, a variation has to be adapted to its social environment, and it has to be capable of being passed on through time." That means that a sufficient number of variations must be produced, they must be tested and then selected, and they can then stimulate other variations over time. Artists tend to enjoy greater degrees of freedom in such an urban environment, making a deepening of their artistic practice and identity more probable.

\section{Increasing and self-feeding networks}

46 An important aspect in the area of urban evolution is the process of positive feedback (Allen \& Sanglier, 1981). Positive feedback means that developments react upon themselves and thereby magnify their effect. This model also speaks of increasing returns. The artist Sui Jianguo, based in Beijing, illustrates the evolution of such increasing returns as follows: "When...as the first step we came in, we just want to work here because it's quiet and there were some small restaurants and it's convenient to eat, then came back to work and it's close to the school, very convenient. So then when Robert came, some artists came. When some artists, when they came, they tried to know everything so they talked with...I don't know the English name, either the landlord of the company, they talked with Sam. They know...they can rent and what kind of price. So in one year, many artists came." The growing number of artists and their high level of productivity have a self-fuelling effect in terms of things becoming even richer and more complex. The artist Amy Sillman, based in Williamsburg, describes this as follows: "I mean, of course there's always a value or something [that] is produced from that situation which does stay, you know, compelling. Because if a bunch of people all start living in a neighbourhood together and then they start to make a magazine or a space or a thing, they also then have lots of friends and they want to live near their friends." As a result, the artists become well-connected and, due to their productivity, create many works for exhibit. In Williamsburg, several grassroots galleries appeared that became local centres for critical discussions and meeting places, such as Pierogi or Front Room.

In 798, open studies and festivals were organised that were attended by international visitors. These activities and events attracted other artists who would like to participate in such a setting and also increase their output, develop their identity or maximise their careers. For instance, the art bookshop and publisher Timezone 8 opened in 798 in 2001. Many artists at the art academy worked for the bookshop, and as a consequence, opened their studio spaces in the area. Furthermore, the artists begin to create so-called third spaces such as cafés and music venues or local art magazines, which reinforced these networks. Perhaps this development could be considered well researched. However, most of the initial artists who moved to the area were mid-career artists and already had connections through which they could show or exhibit their art. The creation of the spaces should not simply be considered an extension of well-established venue formats into those areas, but rather as from of decoupling. The decoupling enables these venues to gain legitimacy, because they refer to concepts that exist elsewhere while simultaneously maintaining an internal flexibility that can incorporate distinct local development (Meyer \& Rowan, 1977). The evolutionary decoupling seems to be a decisive quality that can really set off and foster unique developments. Artists may build up a reputation, because the decoupling provides an image that depicts them as non- 
mainstream, fresh or different due to their localisation to a particular area while at the same time relating this particularity to wider aesthetic norms. Thus, inventions are transformed into innovations. There is, of course, no guarantee of success or the best possible development, but the chance of other developments becomes more unlikely, because this process is, to a certain extent, locked in. This quality of the lock-in enables the stabilising of some urban artistic activities and the development of a more coherent image of the district, providing a symbolic resource for self-definition.

\section{Images of the self and the other}

With the growing number of artists and growing self-recognition, the community starts to observe itself and tries to make sense of the artists' activities. An important source in this process is the early grassroots magazines (Magakon, 2010). For instance, in Williamsburg, the broadsheet and later on, journal, Brooklyn Rail, became quite influential. The newspaper represented "slanted opinions designed to be read on the L train back and forth to Manhattan [and] was to provide an open forum for criticism of the arts, politics, and the world around us" (Hamm, n.d.). Historically, this self-observation required that the production and consumption of art were not solely designated to private places but were, in principle, more open and accessible to other artists through relevant institutions or squares and similar places (Gunn, 2008).

The increased potential for self-observation is handled in relation to the location and in contrast to other areas of the city. For instance, Matt Freedman, an artist based in Bushwick (which is on the other side of the city), stated, "I came here to see the freak show [September opening in Chelsea, with Chelsea being in contrast to Bushwick]." Another example about the location itself is reflected in the statement by Sui Jianguo, an artist based in Beijing: "So when I work in the space like 798, I feel very good." This process of self-recognition and comparison could be described as a process of urban narrativisation, in which different types of urban imaginaries are created (see Matthews, 2008). Thus, urban imaginaries of the real and authentic do not develop only with regard to the artists themselves but also with regard to other imaginaries of the city. In this context, Daniel Aycock states, “Chelsea's press, they'll always mention Williamsburg in some kind of negative light, which I think is funny because obviously they're much bigger. There's many more galleries, the bigger galleries there make so much more money, why do they even need to mention Williamsburg? They are threatened, I guess. Yeah, why go after the underdog?" This evolutionary trend results in a form of secondorder observation. This type of observation is based on an observation that observes how one is observed by other observers and can thereby adjust observations, which may result in the stabilisation of mutually shared expectations (Von Foerster, 1976). On that basis, projections of new symbolic urban material can develop and thereby influence the overall urban symbolic configuration of the city and its neighbourhoods (see Harris, 2012).

This section of the paper has identified four aspects that address the morphogenesis of art districts, in particular, from the perspective of their unlikely growth and spread. The first aspect discussed how a heterogonous evolutionary state is problematic for the evolution of art districts. The symmetrical spread of possibilities results in an oscillation, where both commitment and non-commitment are risky, leading to a stalemate. It is, in particular, the original urban configuration and its access to different spaces across the city that can introduce an asymmetrical element that thereby gives preference to a particular location. Furthermore, the loose coupling of artistic activities that might 
emerge from this has the disadvantage of being disconnected from an urban artistic infrastructure. The loose coupling may result in strict couplings and therefore more selective complexity if evolutionary universals can provide an integration of these differentiated settings. The evolutionary attractors (architecture, access or image) need to perform a double function that also shields or protects the artists from more dominant urban imaginaries. (These attractors may be unattractive to a wider audience or excluded from rapid urban upgrading). The loose coupling requires a niche setting in which an experimental morphogenesis is given sufficient time. This precondition may explain why some spots in a city have a greater potential to attract certain artists and to trigger processes of accumulation of more artistic activities by shielding them from wider urban developments. The urban configuration of the district has an evolutionary anchoring effect (Kahneman \& Tversky, 1984).

It seems that the loose coupling of artistic activities may arise in different districts of the same city and may also develop more often in large metropolitan areas. The spatial mutual awareness and symbolic transformation require even higher levels of complexity. The evolutionary niche needs to be integrated and embedded into wider structures of the art world that can initially channel these developments. However, the important aspects is that of an evolutionary decoupling. The mutual awareness is transformed into a network of like-minded people who really engage in mutual activities. Under these conditions, artists are less likely to give up, because they receive motivation and support from friends. This small initial network of friends can arise and may enable a symbolic transformation of the district. A safe zone is created into which more and more artists can enter. The decoupling is a highly risky stage. The community might disintegrate if no symbolic context arises that unites them. Third places are important evolutionary structures, as they provide a density and platform that may channel these selfobservations and comparisons. Variations can be reinforced and presented to newcomers. This morphogenesis leads to a change in the urban landscape that sees new places of cultural consumption emerge. This attracts further artists, critics and a broader audience, and increasing returns become possible, but this is also where the direction of the development becomes locked in (Arthur, 1994).

\section{Third barrier. the improbability of creative and artistic districts in the long run}

"He [a dealer] came in here and he was expecting to see a whole new bunch of pixilated paintings and he was going to probably show them in his gallery. Instead he saw these acorns that hadn't even...there was nothing, it was just dirt. In a nutshell he said, no pun intended, "Aron, you're shooting yourself in the foot with this one. You've got a career, if you make this change now at your age you're done."' (Aron Namenwirth, artist based in Williamsburg)

With the creation of an image, community or style, the district is confined within a particular frame, thus limiting what can be done, limiting the freedom of expression and creativity. However, one could ask why this is problematic, in that the artists could simply break away from the district's image and its path dependence and create something else. The common image of the artist as one who breaks the rules and who is the inventor or creator of such structures would support such a development. However, what we often find is that the artists engage in a struggle to preserve the district as it is or document it from a perspective of decline, with the original and authentic atmosphere 
being lost due to gentrification. If we want to understand the growth and decline of complexity with regard to the question of the path dependence of symbolic images of art districts, it is necessary to relate their urban embedding to the wider structures of the art world. Although the art world fosters an image of artists as breaking away from or inventing new rules, this image is closely related to their being embedded in a particular urban artistic milieu, which assures that the relevant painting, song or text contains an innovative quality. In other words, the innovative aspect needs to be confirmed by its integration into the urban artistic milieu. This integration has a locked-in quality for the artistic career from which is it is difficult to deviate.

The artist Matt Freedman, based in Bushwick, illustrates this locked-in quality. He was working for a local gallery and was trying to convince the wealthy owner to get more experimental artists and more diversity into the gallery. However, such a variety and constant change of artistic stock has considerable consequences for the overall image and art market value. The latter highly depends on a confirmation, or consecration, by various parties in the art world (Bourdieu, 1993). The crucial aspect is therefore, as Freedman states, "to create the appearance of permanence and solidity". This permanence or reliance on the same artists over a particular time assures the collectors that they are trusted by the consecrated parties and that the selection of these particular artists is based on broader values that will also exist in the future. The crucial aspect is hereby to be loyal to the overall context and artistic project in which the artist is embedded, because this assures the linking of the individual project with art world structures of consecration. Therefore, Freedman can state, "And art galleries sort of have...I mean, this was a relatively, quite a conservative gallery, but even radical galleries, they have to have that ineffable...they're actually selling something besides the object. They're selling the atmosphere or the potential. So I think they have to locate themselves in these sites if they want a certain kind of collector to have faith in them." In can be said that the newness that results from the district leads at the same time to a limitation of future variety.

Additionally, with the ageing of the district, more and more artists from different age groups and generations arise. This growth causes an inner differentiation of the district into different subcultures, subgroups and sub-networks. Although in principle, this increases the complexity of the district, it causes social coherence to decline (Eisenstadt, 1964). This decline in coherence results on the one hand from the increasing number of artists who cannot be linked into mutually stimulating processes. The artist James Clark (based in Williamsburg) states, "As the community got larger and the amount of artists came in it got more of this... it gets more fractured so the interaction becomes fractured."

The decline in coherence also results from a diversification of professional interests and institutions, with some of them being only partially engaged with artistic production. This development is described by the artist Cang Xin (based in Beijing): "751 [a part of 798] is dedicated to design and advertisement companies. But not to contemporary art." The decline in coherence would require even more complex (and therefore improbable) frameworks to encompass these differentiated activities. As a result, the established image develops into something else, making it less artistic or less clear. It is here that the possibilities for retail development start to emerge, placing their own structures into these gaps, changing the quality even more. A growing trend that stretches out from other parts of the city is mingled into the urban history of the district, blurring its boundaries. The image of being separate and different is slowly broken down. 

facilities for children cause other values - those of the larger society - to take root on the one hand. Eric Heist, owner of the gallery/off space Momenta in Williamsburg, illustrates this development: "I mean, Americans always like to talk about the neighbourhood in terms of the Wild West, like really they were selling crack on the street, there were murderers on the street. You could do anything, you could park anywhere, and then the law came in, and the babies came in, and everything kind of got cramped." On the other hand, the city's social structures begin to reach into the district. It becomes socially closer to the rest of the city, making it less outstanding and thereby lacklustre in the eyes of the artists. For instance, Pi Li, the co-founder of the Boers-Li Gallery based on the edge of 798, states that "before the Olympics is quite interesting, when Huang Rui was moving here. And then there were not so many fashion shops here, the gallery studio here. And unfortunately, the rent is too high, the artists moved to more farther [sic, distant] place, and then...then it's become...became very boring."

Thus, the decline of art districts cannot solely be explained by a rent-gap thesis and flow of economic capital into the area. The growth in social complexity of the district, its historical baggage and its urban fabric (social differentiation) create a path dependence through which the district achieves its outstanding quality and artistic novelty, but which then also limits the exploration of possibilities outside of this frame. However, the image of a productive district attracts other artists who share a different understanding or cluster around issues other than production, which might include developing an artistic lifestyle or working towards a career or simply producing works. The social coherence of the early community is broken down into various groups, which opens the social space to corresponding developments, such as the opening of clubs, bookshops, art magazines, venues or second-hand clothing shops. On top of these more commercial activities, new symbolic frames arise that make the district attractive to investment from the outside. These activities are often associated with an overall decline in creativity or are painted in a negative light; however, these also provide a new ground through which art districts can arise elsewhere, when the symbols that are associated with the attractive lifestyle of such an area emerge through developments elsewhere in the city. This suggests that urban history is a far more complex process than some theories of gentrification suggest and that the rise and fall of art districts depend much more on the general urban dynamic than on particular areas.

\section{Conclusion}

Discussion of the urban history of art districts mostly pays attention to processes of gentrification, but it does not provide a model for their development or integration into the wider urban history of the city. This paper attempts to outline some key theoretical arguments for the morphogenesis of art districts and what part the process of gentrification plays. Morphogenesis refers to the evolutionary build-up of complexity as a highly improbable phenomenon. The paper identified three barriers of improbability: 1) how preference is given to a particular area, 2) how a minority can overtake a social majority and 3) how artistic districts can endure in the long term. The two case studies that serve as support for this evolutionary model are Williamsburg, NYC, and 798, Beijing.

The first barrier identified, in principle, three important evolutionary structures. A heterogonous distribution of artistic activities may introduce an asymmetrical element 
due to the overall spatial organisation of urban access and mobility. The access can give rise to a loose coupling of artistic activities. However, urban access is equally important in creating an evolutionary niche in which artistic activities can be fostered and can experiment. Finally, the linkage of the loose coupling with an artistic infrastructure is described as an evolutionary universal that can integrate emerging and existing activities that would otherwise remain divided. Such a setting seems to evolve easily in larger metropolitan areas (Gravereau, 2012).

The overcoming of the second barrier, which can largely be seen as an urban-symbolic transformation of the area into an art district, seems only to occur in a few places. This transformation seems to be based, in particular, on a process of evolutionary decoupling. The decoupling relies on the one hand on the build-up of networks and on the other hand on the formation of venues and platforms for self-observation and comparison. Networks create a safe zone in which artistic variations can be developed through a system of peers that stands apart from established aesthetic norms. Networks provide knowledge and motivation through which these variations can be tested and maintained. Third places, such as venues and magazines, are important structures for second-order observation. Variations can be compared against more established trends in the art world. The district develops a distinctive image where increasing returns become possible but also where the direction of new evolutionary developments becomes locked in.

61 The third barrier shows that such a successful creation of a unique setting limits the future variety of the district. Furthermore, the district is differentiated into sub-groups with different interests and needs, which cannot be integrated by the existing narrative. Ad hoc narratives emerge, mostly in the form of urban resistance. This process of further differentiation becomes unattractive to a range of artists who moved there in the first place or who are in their mid-career stage. They tend to move elsewhere.

It is quite possible that this development still occurs in several cities or has occurred in several cities around the world. The important aspect of this process is that it can be triggered elsewhere in the city, which leads to questions about and research into the wider urban evolution of the city, in particular, with regard to processes of creative destruction and urban rebuilding. It seems that this type of urban dynamic has taken place in only a few global cities. Industries or residential living might shift elsewhere, because conditions have changed or are being improved. Thus, space is opened up that may be occupied by artists. Regions or countries that have a much centralised urban structure might be unable to experience such constant shifts in their urban landscapes. Therefore, it seems necessary that future research not only addresses the morphogenesis of art districts and the current urban dynamic of the city but that it also addresses shifts in the wider urban landscape at national, transnational and global levels.

\section{BIBLIOGRAPHY}

ALLEN P.M., SANGLER M. (1981), “Urban evolution, self-organization, and decisionmaking”, Environment and Planning A, 13, 2, pp. 167-183. 
AMBROSINO C. (2008), Du quartier d'artistes au cluster culturel, perspective londonienne, communication lors du 76e Congrès de l'ACFAS, Québec, 6 et 7 mai 2008.

ARCHER M.S. (ed.) (2013), Social morphogenesis, New York, Springer.

ARTHUR B.W. (1990), "Positive feedbacks in the economy”, Scientific American, 262, pp. 92-99.

ARTHUR B.W. (1994), Increasing returns and path dependence in the economy, University of Michigan Press.

BADER I., SCHARENBERG A. (2010), "The sound of Berlin: subculture and the global music industry", International Journal of Urban and Regional Research, 34, 1, pp. 76-91.

BAILONI M. (2014), “La reconversion des territoires industriels par la culture dans les villes britanniques: un modèle en crise?", Belgeo, 1 [en ligne].

BECKER H.S. (1973), Outsiders, Free Press.

BERGSTROM C.T., DUGATKIN L.A. (2012), Evolution, New York, W.W. Norton \& Company.

BOICHOT C. (2014), “Les quartiers artistiques: territoires en construction. Regards croisés sur Montreuil (Île-de-France) et Neukölln (Berlin)”, Annales de géographie, 4, 698, pp. 1088-1111.

BOURDIEU P. (1993), The field of cultural production: essays on art and literature, New York, Columbia University Press.

CAMERON S., COAFFEE J. (2005), “Art, gentrification and regeneration - from artists as pioneer to public arts", European Journal of Housing Policy, 5, 1, pp. 39-58.

CINTI T. (2007), "Cultural clusters and cultural districts: the state of the art", in COOKE P. and LAZZERETTI L. (eds.), Creative cities, cultural clusters and local economic development (pp. 71-92), Cheltenham, Edward Elgar.

CITY POPULATION (2014), China - Beijing (Available from: http://www.citypopulation.de/ChinaBeijing.html).

CLAVAL P. (1984), “Urban space and freedom”, International Political Science Review, 5, 2, pp. 147-160.

COHEN S. (1991), Rock culture in Liverpool: popular music in the making, Oxford, Clarendon Press.

COLE D.B. (1987), “Artists and urban redevelopment”, The Geographical Review 77, 4, pp. 391-407.

COMUNIAN R., MOULD O. (2014), “The weakest link: creative industries, flagship cultural projects and regeneration", City, Culture and Society, 5, 2, pp. 65-74.

COOKE P. (2007), "Culture, clusters, districts and quarters: some reflections the scale question", in COOKE P. and LAZZERETTI L. (eds.), Creative cities, cultural clusters and local economic development (pp. 25-47), Cheltenham, Edward Elgar.

CSIKSZENTMIHALYI M. (1999), "Implications of a systems perspective for the study of creativity", in STERNBERG R. (ed.), Handbook of creativity, Cambridge University Press, Cambridge.

CURRAN W. (2007), “'From the frying pan to the oven': gentrification and the experience of industrial displacement in Williamsburg, Brooklyn", Urban Studies, 44, 8, pp. 1427-1440.

DENZIN N.K. (1983), “Interpretive interactionism”, in MORGAN, G. (ed.), Beyond method: strategies for social research (pp. 129-147), Beverly Hills, CA, Sage.

DÖRFLER T. (2010), Gentrification in Prenzlauer Berg? Milieuwandel eines Berliner Sozialraums seit 1989, transcript, Bielefeld. 
EISENSTADT S.N. (1964), “Social change, differentiation and evolution”, American Sociological Review, 29, 3, pp. 375-386.

FOORD J. (1999), “Creative hackney: reflections on hidden art”, Rising East, 3, 2, pp. 38-66.

FREEMAN N. (2007), Conceiving the city: London, literature, and art, 1870-1914, Oxford University Press.

GAUBATZ P. (1999), “China's urban transformation: patterns and processes of morphological change in Beijing, Shanghai and Guangzhou”, Urban Studies, 36, pp. 1495-1521.

GEE M., STEWARD J. (1995), “Art and the modern European city: survey and conference report”, Urban History, 22, 2, pp. 181-186.

GLAESER E.L., KAHN M.E., RAPPAPORT J. (2008), "Why do the poor live in cities? The role of public transportation”, Journal of Urban Economics, 63, 1, pp. 1-24.

GLASER B.G., STRAUSS A. (1967), Discovery of grounded theory. Strategies for qualitative research, Sociology Press.

GRANOVETTER M. (1978), "Threshold models of collective behaviour”, American Journal of Sociology, 83, 6, pp. 1420-1443.

GRAVEREAU S. (2012), “Être artiste à Belleville: un détournement 'urbain' des règles de l'art?" Sociologie de l'Art, 19, 1, pp. 75-100.

GREEN N. (1999), “Artists in the East End 1968-1980”, Rising East, 3, 2, pp. 20-37.

GREGORY D. (2000), “Morphogenesis”, in JOHNSTON R.J., GREGORY D., PRATT G. and WATTS M. (eds.), Dictionary of human geography, Oxford, Blackwell, $4^{\text {th }}$ edition.

GU C., SHEN J. (2003), "Transformation of urban socio-spatial structure in socialist market economies: the case of Beijing”, Habitat International, 27, 1, pp. 107-122.

GUILBAUT S. (ed.) (1990), Reconstructing modernism: art in New York, Paris and Montreal 1945-1964, Cambridge, MIT Press.

GUNN S. (2008), “'How Manchester is amused': the cultural economy of the industrial city", in HESSLER M. and ZIMMERMAN C. (eds.), Creative urban milieus: historical perspectives on culture, economy and the city, University of Chicago Press, Chicago.

HAMM T. (n.d.), A brief history of the Brooklyn Rail, (Available from: http://www.brooklynrail.org/ history).

HANQUINET L., SAVAGE M., CALLIER L. (2012), "Elaborating Bourdieu's field analysis in urban studies: cultural dynamics in Brussels", Urban Geography, 33, 4, pp. 508-529.

HARDIN G. (1960), “The competitive exclusion principle”, Science, 131, 3409, pp. 1292-1297.

HARRIS A. (2012), “Art and gentrification: pursuing the urban pastoral in Hoxton, London", Transactions of the Institute of British Geographers, 37, 2, pp. 226-241.

HUANG R. (ed.) (2004), Beijing 798: reflections on art, architecture and society in China, Timezone 8 and Thinking Hands.

HUDSON J.R. (1988), "Pioneer artists and middle class settlers: lifestyle variables and neighborhood succession", Journal of Family and Economic Issues, 9, 3, pp. 250-263.

HUNG W. (2008), Making history, Beijing, Timezone 8.

KAHNEMAN D., TVERSKY A. (1984), “Choices, values, and frames”, American Psychologist, 39, 4, pp. 341-350. 
KIM H. (2007), "The creative economy and urban art clusters: locational characteristics of art galleries in Seoul", Journal of the Korean Geographical Society, 42, 2, pp. 258-279.

KROPF K.S. (2001), “Conceptions of change in the built environment”, Urban Morphology, 5, 1, pp. 29-42.

LEFEBVRE H. (1991), The production of space, Blackwell Publishing.

LEFÈVRE C. (2010), “The improbable metropolis: decentralization, local democracy and metropolitan areas in the Western world”, Análise Social, 45, 197, pp. 623-637.

LEY D. (2003), “Artists, aestheticisation and the field of gentrification”, Urban Studies, 40, 12, pp. 2527-2544.

LUHMANN N. (2012), Theory of society, Volume 1, Stanford University Press.

MAKAGON D. (2010), "Bring on the shock troops: artists and gentrification in the popular press", Communication and Critical/Cultural Studies, 7, 1, pp. 26-52.

MATHEWS V. (2000), “Artcetera: narrativising gentrification in Yorkville, Toronto”, Urban Studies, 45,13 , pp. $2849-2876$.

McFARLAND G.W. (2005), Inside Greenwich Village. A New York City neighborhood, 1898-1918, Amherst, University of Massachusetts Press.

MEYER J. W., ROWAN B. (1977), “Institutionalized organizations: formal structure as myth and ceremony," American Journal of Sociology, 83, p. 340-363.

MILES M. (1995) “Art and urban regeneration”, Urban History, 22, 2, pp. 238-252.

MOLOTCH H., TRESKON M. (2009), “Changing art: SoHo, Chelsea and the dynamic geography of galleries in New York City", International Journal of Urban and Regional Research, 33, 2, pp. 517-541.

MONTGOMERY J. (2003), “Cultural quarters as mechanisms for urban regeneration. Part 1: conceptualising cultural quarters", Planning, Practice \& Research, 18, 4, pp. 293-306.

MORIN E. (1977), La methode I: la nature de la nature, Paris, Seuil.

NEWMAN M.E.J. (2003), "The structure and function of complex networks", SIAM Review, 45, 2, pp. 167-256.

PADGETT J.F., ANSELL C.K. (1993), "Robust action and the rise of the Medici, 1400-1434", The American Journal of Sociology, 98, 6, pp. 1259-1319.

PALENZUELA J. C. (1986), Les Artistes Vénézuéliens à Paris : 1920-1939 (PhD Dissertation), Université de Paris 8.

PARK R.E. (1928), "Human migration and the marginal man", The American Journal of Sociology, 33, 6, p. 890.

PARSONS T. (1964), "Evolutionary Universals in Society”, American Sociological Review, 29, 3, pp. 339-357

PFLAUM W. (n.d.), “Williamsburg, Brooklyn - History”, New York Architecture (Available from: http://www.nyc-architecture.com/WBG/wbg-history.htm, accessed 15 Oct 2013).

PRATT A.C. (2009) 'Urban regeneration: from the art "feel good' factor to the cultural economy: a case study of Hoxton, London", Urban Studies, 46, 5-6, pp. 1041-1060.

REN Y. (2008), “Architecture and China's urban revolution”, City, 12, 2, pp. 217-225. 
SANTAGATA W. (2002), "Cultural districts, property rights and sustainable economic growth", International Journal of Urban and Regional Research, 26, 1, pp. 9-23.

SAXENIAN A. (1996), Regional advantage: culture and competition in Silicon Valley and Route 128, Cambridge, MA, Harvard University Press.

SHANK B. (1994), Dissonant identities: the rock'n'roll scene in Austin, Texas, Hanover, London, Wesleyan University Press.

SIMPSON C.R. (1981), Soho: the artist in the city, Chicago, The University of Chicago Press.

SKYRMS B. (2004), The stag hunt and the evolution of social structure, Cambridge, Cambridge University Press.

SKYRMS B. (2014), Social dynamics, Oxford, Oxford University Press.

SMITH C.J. (2008), "Monumentality in urban design: the case of China”, Eurasian Geography and Economics, 49, 3, pp. 263-279.

SMITH N., WILLIAMS P. (1986), Gentrification of the city, London, Allen \& Unwin.

SPENCER H. (1898), “What is social evolution?” The Nineteenth Century, 44, pp. 348-358.

STERN M.J., SEIFERT S.C. (2010), "Cultural clusters: the implications of cultural assets agglomeration for neighborhood revitalization", Journal of Planning Education and Research, 20, 10, pp. 1-18.

SUNDO J., GALLOUJ F. (2000), "Innovation as a loosely coupled system in services", International Journal of Services Technology and Management, 1, 1, pp. 15-36.

TAN M., LI X., XIE H., LU C. (2005), “Urban land expansion and arable land loss in China - a case study of Beijing-Tianjin-Hebei region", Land Use Policy, 22, 3, pp. 187-196.

VIVANT E., CHARMES E. (2008), "La gentrification et ses pionniers. Le rôle des artistes off en question", Métropoles, 3, pp. 29-63.

VON FOERSTER H. (1997). “Objects: tokens for (Eigen-)behaviors”, ASC Cybernetics Forum, 8, 3-4, pp. 91-96.

WU W. (2005), Dynamic cities and creative clusters, World Bank Policy Research Working Paper 3509.

ZUKIN S. (1982), Loft living: culture and capital in urban change, Baltimore, Johns Hopkins University Press.

\section{NOTES}

1. The terms "organic" or "preplanned" are often used in this context, but do not remain very clear. In this context, the term "preplanned" designates municipal or governmental strategies and, therefore, a top-down perspective of urban development. "Organic" refers to more localised activities and how they impact on urban change, which represents a more bottom-up perspective. In this sense, both terms involve elements of planning and spontaneous developments.

2. A common economic theory of urban change is explained through the rent gap. This theory derives from the work of the human geographer Neil Smith (Smith \& Williams, 1986), who explained urban change as an economic process based on fluctuating capital investment in urban space. The underlying logic of the rent-gap theory is that suburban development is driven by the 
profit margins on cheap land. The less popular areas are inhabited by poorer sectors of the urban population, often resulting in poor upkeep of the properties in those areas. The depressed land is devalued, with significantly lower rents. There is thus the potential that with better use, higher profit margins could be achieved. Because artists tend to have low income margins, they move into these areas, as they cannot afford the high rent in the city centre. In other words, they basically move there because it is cheap. Their move into these areas may trigger the abovementioned effects, causing the artists to have to move again into other areas with lower rents, and so forth

3. This notion of decline and rise does not suggest that a death and rebirth model is working, but simply suggests that the decline or closure caused a high concentration of artists to dissolve, and suddenly, large numbers of artists required a new place. It is also possible to imagine that other factors can contribute to such a rise in numbers, for instance, through the foundation of a new art school or shifts in the art market.

\section{ABSTRACTS}

This paper will develop a general framework for the cultural evolution of art districts based on empirical research from different global city-regions. It will go beyond gentrifying approaches, which tend to focus on the decline of an art district or area but do not relate this transformation to the overall evolution of a city.

The framework is based on the evolutionary concept of morphogenesis as the formation of increased social complexity. This build-up of complexity will be illustrated through stages through which art districts develop and the inherent logic which contributes to their decline, discussing each stage's morphogenetic features, shedding light on the embedding of districts into urban centres and on urban change.

This paper will compare the development of Williamsburg, New York City, and 798, Beijing. These cases were analysed through a Grounded Theory approach, with the aim to advance our understanding of urban cultural evolution with regard to developing an approach beyond gentrification.

Issu d'un travail de recherche empirique, cet article propose un cadre général à l'analyse de l'évolution culturelle des quartiers artistiques de différentes métropoles mondiales. Il propose de dépasser l'entrée par les seuls processus de gentrification, souvent axée sur le déclin des concentrations artistiques et sans lien avec l'évolution de la ville dans son ensemble.

L'étude est construite autour du concept évolutif de morphogénèse comme facteur de complexité sociale croissante. Celle-ci est illustrée à travers les différentes phases de développement des quartiers artistiques et les logiques inhérentes qui contribuent à leur déclin, analysant les caractéristiques morphogénétiques de chaque étape et l'intégration des quartiers dans l'espace urbain et ses transformations.

L'article compare le développement de Williamsburg à New York et du quartier 798 à Beijing, dans une perspective empirique visant à faire progresser la compréhension des processus d'évolution culturelle urbaine, au-delà des approches par les phénomènes de gentrification. 
INDEX

Mots-clés: dynamiques urbaines, quartiers artistiques, gentrification, morphogénèse, 798 (Beijing), Williamsburg (NYC)

Keywords: urban change, art districts, gentrification, morphogenesis, Beijing 798, WilliamsburgNYC

\section{AUTHOR}

\section{CHRISTIAN MORGNER}

Lecturer in International Communication and Culture, School of Modern Languages, University of Leicester, cm570@leicester.ac.uk 